\title{
Evacuation of hematomas using liposuction technology: Technique and literature review
}

\author{
Michael SG Bell MD, Gaby Doumit MD
}

MSG Bell, G Doumit. Evacuation of hematomas using liposuction technology: Technique and literature review. Can J Plast Surg 2006;14(1):51-52.

Established nonexpanding hematomas can be successfully treated with minimal morbidity using standard liposucstion techniques at the bedside or in an outpatient setting under local anesthesia. The authors presents a series of eight patients and discuss current concepts of dealing with this common and distressing surgical complication.

\section{Évacuation d'hématomes par liposuccion : technique et examen de la documentation}

Key Words: Charlie horse (intramuscular hematoma); Evacuation; Hematoma; Liposuction

A hematoma is a common complication of surgical procedures. A large, expanding hematoma can result in necrosis of the overlying skin $(1,2)$ or adjacent subcutaneous fat, increased incidence of infection, scarring, skin hyperpigmentation, tissue edema and a prolonged convalescence. There have been only a few reports dealing with conservative evacuation of a hematoma using liposuction technique (1-7), mostly for the evacuation of a lower extremity hematoma following trauma. A series of six cases of hematomas of the breast and abdomen following surgery, which were successfully and simply drained by the tulip liposuction apparatus (The Tulip Company, USA), is presented. In one patient, a hemovac drain was left in situ to prevent further hematoma formation. Patients with a seven-month-old lateral thigh hematoma and an adductor muscle hematoma, respectively, are also included in the series.

The tulip liposuction system is well known and commonly used by plastic surgeons for liposculpturing. It has the distinct advantage of simply using a syringe to which a vacuum is applied by a lock on the plunger (Figure 1). The custom-designed cannulas fit on a disposable syringe, and come in a variety of sizes and lengths.

The authors have used this system, without adaptation, on eight occasions to drain stable hematomas. Four of these occurred in the breast: two after breast reduction, one postgynecomastia excision and one after capsulotomy and removal of old silicone breast implants. Three occurred after abdominoplasties, and a single lateral thigh hematoma was also treated.

\section{TECHNIQUE}

This is a very simple procedure to undertake in all cases. The hematoma is injected with $0.3 \%$ xylocaine, with adrenaline (30 $\mathrm{mL}$ to $60 \mathrm{~mL}$ ) and left for $20 \mathrm{~min}$. A stab incision is made with a \#11 blade and a tulip liposuction cannula is inserted into the hematoma. This is a painless procedure in each case. The clot is removed by moving the cannula proximally and distally, as well as simply rotating it. There is no tendency for the clot to block the cannula, and it is estimated that virtually all of the fluid is effectively removed. In the four cases in which no drain was inserted, no reaccumulation of the hematoma occurred. A $3 \mathrm{~mm}$ and a $3.7 \mathrm{~mm}$ cannula were used with success.

A hematoma of $202 \mathrm{~mL}$ was evacuated after a breast reduction performed $24 \mathrm{~h}$ previously; in this situation, a hemovac tube was inserted into the stab incision used for the liposuction cannula. The tube was placed over a $3 \mathrm{~mm}$ tulip cannula, used as a stylet, which guided the tip into the hematoma cavity. This was done to ensure that the entire cavity was evacuated because the breast was still approximately 30\% larger than the opposite side. The other five cases had recognized hematomas on a more delayed basis, between four and seven days postoperatively. The largest postsurgery hematoma was evacuated from the abdomen at one week, and, in fact, was rather serosanguinous with a volume of $500 \mathrm{~mL}$. In this situation, a Penrose drain was inserted because a hemovac drain was not available.

Although standard liposuction technique could be performed under local anaesthesia, the tulip liposuction system is more easily available and portable and can be used on the ward, and in the outpatient or emergency department.

\section{DISCUSSION}

Few studies examining the standard liposuction technique for evacuation of hematomas have been published in the literature. Dowden et al (2) used a high vacuum liposuction cannula successfully in three patients with lower extremity hematomas secondary to trauma. They recommended the standard liposuction 


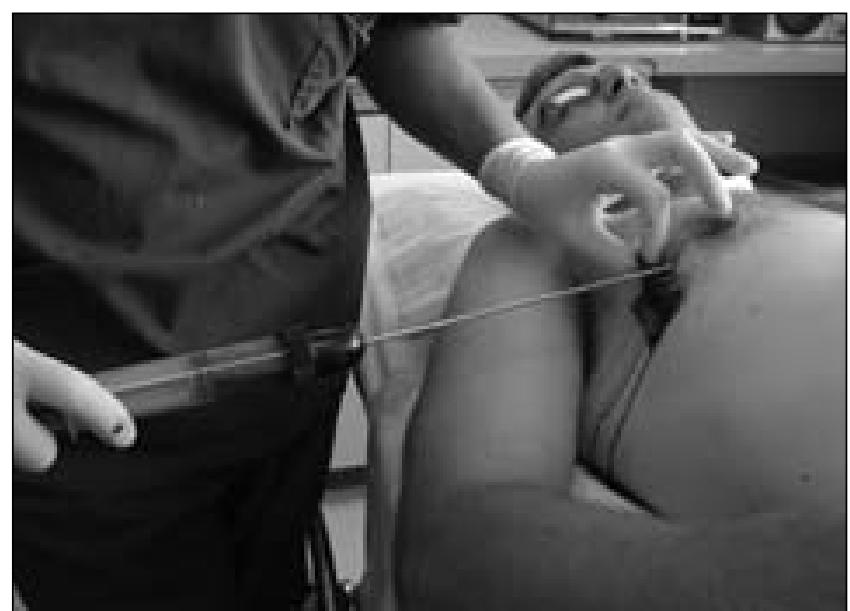

Figure 1) The tulip liposuction system

technique for evacuation of coagulated or viscous persistent subcutaneous hematomas. Olivier et al (1) evacuated a trochanteric hematoma in a 73-year-old patient on coumadin, after tumescent infiltration with a solution of normal saline, adrenaline and hyaluronidase. They advocated that the tumescent infiltration technique for liposuction improved safety and allow large areas to be treated under local anesthetic. Yeow et al (6) suctioned a hematoma of the right cheek, following rhytidectomy, using endoscopically assisted standard liposuction under general anesthesia. The endoscope permitted the visualization of residual bleeding points, and facilitated hemostasis with the application of fibrin glue or thrombin glue.

We propose that intramuscular hematomas, which occur so frequently in athletes, may lend themselves to this relatively noninvasive procedure, which has infinitely less morbidity than an open surgical approach. We have experience with only one case, but suggest that this could be a useful technique to employ for a stabilized hematoma in an intramuscular site.

\section{REFERENCES}

1. Oliver DW, Inglefield CJ. Liposuction of haematoma. Br J Plast Surg 2002;55:269-70.

2. Dowden RV, Bergfeld JA, Lucas AR. Aspiration of hematomas with liposuction apparatus. A technical note. J Bone Joint Surg Am 1990;72:1534-5.

3. Fahmy FS, Moiemen NS, Frame JD. Liposuction for drainage of large haematoma. Injury 1993;24:61-2.

4. Ascari-Raccagni A, Baldari U. Liposuction surgery for the treatment of large hematomas on the leg. Dermatol Surg 2000;26:263-5.
This case involved a $1 \mathrm{~L}$ hematoma in the adductor magnus muscle treated successfully by an orthopedic colleague in an identical manner. No drain was used, and the patient recovered remarkably quickly, with instant relief of pain.

Our largest hematoma treated occurred in the lateral thigh in a woman on coumadin in a motor vehicle accident. She could not lie on her side and had constant discomfort, not improving after seven months of careful medical evaluation. The hematoma was drained in approximately $15 \mathrm{~min}$ as an outpatient procedure, under local anesthesia, removing $2250 \mathrm{~mL}$ of dark liquid. The skin had been stretched and expanded by the marked swelling, but the simple atraumatic drainage procedure was successful. We tried to insert a hemovac drain into the cavity but could not. The fluid reformed slowly, necessitating a second drainage of $1200 \mathrm{~mL}$ eight weeks later. A hemovac inserted on this occasion drained only scant amounts of fluid for almost five days. Unfortunately, over six weeks, the fluid had again accumulated but the volume was significantly smaller and the patient was more comfortable. She declined an additional attempt.

\section{CONCLUSION}

The author's experience would lead the conclusions that at $24 \mathrm{~h}$ following surgery, when a hematoma seems established and is not expanding, that simple liposuction technique will remove the bulk of the fluid and is an appropriate and safe procedure. This should be distinguished from the situation in which an expanding hematoma is recognized, and in this circumstance, the patient should probably be treated in the traditional fashion by being returned to the operating room to identify and control a bleeding vessel. When active bleeding has stopped, with the tamponade effect from a hematoma, liposuction technology has become our procedure of choice.

The authors present these eight cases to encourage others to try this safe and atraumatic technique, which will reduce morbidity and simplify hematoma treatment.

5. McEwan CN, Jackson IT, Stice RC. The application of liposuction for removal of hematomas and fat necrosis. Ann Plast Surg 1987;19:480-1.

6. Yeow VK, Huang MH. Endoscopically assisted suction evacuation in the surgical treatment of subcutaneous hematomas. Plast Reconstr Surg 1998;101:2016-7.

7. Goldberg LH, Humphreys TR. Surgical pearl: Using the liposuction cannula/syringe apparatus for conservative evacuation of postoperative hematomas. J Am Acad Dermatol 1996;34:1061-2. 